\title{
Strength Characteristics of Inoculated and Nodularised Thin Wall Ductile Iron Castings
}

\author{
Ezenwanyi Fidelia Ochulor ${ }^{*}$, Samson Oluropo Adeosun'1, \\ Mohammed Olawale Hakeem Amuda1, Sanmbo Adewale Balogun' \\ ${ }^{1}$ Department of Metallurgical and Materials Engineering, University of Lagos, Lagos, Nigeria \\ ${ }^{2}$ Department of Mechanical and Biomedical Engineering, Bells University of Technology, Ota, Nigeria \\ Email: ${ }^{*}$ fochulor@yahoo.com
}

Received 2 March 2015; accepted 13 March 2015; published 16 March 2015

Copyright (C) 2015 by authors and Scientific Research Publishing Inc.

This work is licensed under the Creative Commons Attribution International License (CC BY). http://creativecommons.org/licenses/by/4.0/

c) (i) Open Access

\begin{abstract}
Carbide precipitates in Thin Wall Ductile Iron (TWDI) used for automotive applications needs to be eliminated or reduced for improved strength, ductility, crack propagation resistance and good machinability. Ductile iron thin section profiles $(\leq 3 \mathrm{~mm})$ present danger of massive carbide precipitations in the as-cast sample. Precipitated carbide phase is brittle and negatively affects the mechanical properties of the iron matrix. The suppression of carbide formation is associated with the nucleating properties of the nodularizer and innoculant alloys. This treatment is vital in ensuring that carbide precipitation, flake graphite structure and non-nodular graphite phases are reduced or completely eliminated in the TWDI castings. Therefore, the temperature and technique of treatment would influence the yield of the process, and ultimately the mechanical properties. In this study, the effect of nodularization and inoculation treatment temperature on the microstructure and mechanical properties of TWDI castings is examined. The results indicate that good nodularity and nodule count with better percent elongations are achieved using low treatment temperatures in descending order of $1490^{\circ} \mathrm{C}, 1470^{\circ} \mathrm{C}$ and $1450^{\circ} \mathrm{C}$, but have negative effect at lower treatment temperature of $1430^{\circ} \mathrm{C}$. However, TWDI castings have superior properties in terms of nodule counts and nodularity at $1450^{\circ} \mathrm{C}$. Treatment temperature does not produce significant influence on ultimate tensile strength (UTS) and hardness of TWDI castings. TWDI castings show poor nodularity, nodule count and ductility at higher inoculation treatment temperatures of $1550^{\circ} \mathrm{C}, 1530^{\circ} \mathrm{C}$ and $1510^{\circ} \mathrm{C}$.
\end{abstract}

\section{Keywords}

Thin Wall Ductile Iron (TWDI), Nodularization, Inoculation, Graphite Structure

\footnotetext{
${ }^{*}$ Corresponding author.

How to cite this paper: Ochulor, E.F., Adeosun, S.O., Amuda, M.O.H. and Balogun, S.A. (2015) Strength Characteristics of Inoculated and Nodularised Thin Wall Ductile Iron Castings. Journal of Minerals and Materials Characterization and Engineering, 3, 94-105. http://dx.doi.org/10.4236/immce.2015.32012
} 


\section{Introduction}

In the production of sound Thin Wall Ductile Iron (TWDI) castings, adequate melt treatment involving efficient inoculation and nodularization are imperative. There should be synergy between these two important treatments for the production of good nodularity, high nodule count and carbide free TWDI. Nodularization treatment is carried out first and followed by a two step inoculation treatment. Nodularization treatment is a modification treatment where the shape of the graphite is changed from flake to spheroid or nodules. This shape is responsible for the peculiar properties of ductile iron. Inoculation is followed immediately to facilitate heterogeneous nucleation for increase nodule count and suppression of carbide formation. Prior to the nodule treatment, it is important to ensure the melt is very low in sulphur $(0.01 \% \leq \mathrm{S} \leq 0.03 \%)$. The ferroalloys of ferrosilicon-magnesium and ferrosilicon used for these treatments have fading tendencies. Thus, the melt have to be poured into the mould within a maximum period of seven minutes after the nodularization treatment is done or the treatments would be ineffective. Temperature and treatment technique would affect nodularity and nodule count which in turn influences mechanical properties. The suppression of carbide formation is associated with the nucleating properties of the nodularizer and innoculant alloys. The nucleating property is understood as the number and potency of nuclei formed by the alloy addition. The nodularizer and innoculant additions also influence ductile iron solidification shrinkage [1].

Ductile Iron application for lightweight components is being limited by inability to produce as-cast carbide free thin $(\leq 3 \mathrm{~mm})$ wall parts [2]. This inability results from the formation of large volumes of carbide precipitates, poor nodularity and nodule count, presence of non-nodular graphite structures and undesired matrix types in the cast TWDI part. Borrajo et al. [3] observed appreciable increase in nodule count when cooling rate increased, as a consequence of the thin walls. The observation is possible because of the under-cooling that takes place during solidification of the thinner sections, which activates a larger number of substrates for heterogeneous nucleation of graphite.

The fast cooling of thin section ductile iron castings requires special consideration to produce carbide-free castings [4]. The common feature that all ductile irons share is the spherical shape of the graphite nodules. These graphite nodules are nucleated on small inclusions during solidification [5]. The relative possibilities for nucleation and growth depend upon foreign particles in the melt, whether as trace impurities or as deliberate additions [6]. The amount and form of graphite in ductile iron are determined during solidification and cannot be altered by subsequent heat treatment. The principal factor in determining the different grades of ductile iron in specifications is the matrix structure [7]. In the as-cast condition the matrix will consist of varying proportions of pearlite and ferrite, these can be further altered by heat treatment.

Pouring very thin sections ductile iron presents danger of massive carbide precipitation [8]. The time after spheroidal treatment (holding time) has significant effect on the elongation, but negiligble effect on the tensile strength and hardness of TWDI castings. The graphite shape is also influenced by the holding time [7]. The wall thickness of spheroidal graphite cast iron has very strong effect on the graphite size and shape of the castings [9].

Bockus and Dobrovolskis [10] studied production of ferritic ductile iron castings. The result shows that it is very difficult to obtain thin section of ferritic ductile iron as-cast, as it is associated with high solidification rate and formation of carbides. The investigation reveals that ductile iron castings will be ferritic (as-cast) only when large amounts (more than 50 percent) of pig iron are used in the charge.

In the production of quality cast irons the inoculation process is of vital importance. When comparing un-inoculated and inoculated irons, differences in microstructure are easily revealed with strong effect on the final mechanical properties of the casting. Through inoculation the graphite nucleation and eutectic under-cooling of the iron can be controlled and this will be of crucial importance in giving the iron its required service properties [11]. Inoculation introduces additional nuclei which cause graphite precipitation and reduces the under-cooling and formation of carbides [12].

Works on composition, [13]-[16], treatment techniques [7] [12] and [17] and frequency [18] have been carried out to determine the best way to carry out these treatments. However, earlier studies lacked information on the appropriate temperature at which the nodularization treatment should be done for best yield and magnesium recovery.

This study presents a molten metal processing technique for treatment temperature that eliminates primary carbides and non-nodular graphite structures in pearlitic-ferritic ductile iron castings useful for automotive applications. 


\section{Experimental Methodology}

Seven treatment temperatures namely $1550^{\circ} \mathrm{C}, 1530^{\circ} \mathrm{C}, 1510^{\circ} \mathrm{C}, 1490^{\circ} \mathrm{C}, 1470^{\circ} \mathrm{C}, 1450^{\circ} \mathrm{C}$ and $1430^{\circ} \mathrm{C}$ are studied to determine best properties and microstructure. The charge materials consist of mild steel scraps, ductile iron returns, ferrosilicon and graphite as shown in Table 1. The requirements of ASTM E2349 standard mould making procedures are employed using adequate moulding equipment to produce dense moulds. The moulding sand consists of silica sand, bentonite, additives (coal dust and starch) and water. The dimensions of the drag and cope are $410 \mathrm{~mm} \times 375 \mathrm{~mm}$ with a height of $110 \mathrm{~mm}$. The patterns for the cavity, runners and in-gates are placed in the drag section and rammed adequately while the sprue pattern of height $100 \mathrm{~mm}$ is placed in the cope. The pressurized casting technique is used with ratio of 3:2:1 which translates to cross sectional area at sprue: cross sectional area at runner: cross sectional area at ingate.

The molten metal is first tapped at $1555^{\circ} \mathrm{C}$ into a preheated treatment ladle for the first treatment temperature of $1550^{\circ} \mathrm{C}$ using the sandwich method. The treatment alloy used 12 - $16 \mathrm{~mm}$ ferrosilicon magnesium granules covered with steel scraps and placed at the bottom of the ladle. This same procedure is repeated for treatment temperatures of $1530^{\circ} \mathrm{C}$ tapped at $1535^{\circ} \mathrm{C}, 1510^{\circ} \mathrm{C}$ tapped at $1515^{\circ} \mathrm{C}, 1490^{\circ} \mathrm{C}$ tapped at $1495^{\circ} \mathrm{C}, 1470^{\circ} \mathrm{C}$ tapped at $1475^{\circ} \mathrm{C}, 1450^{\circ} \mathrm{C}$ tapped at $1455^{\circ} \mathrm{C}$ and $1430^{\circ} \mathrm{C}$ tapped at $1435^{\circ} \mathrm{C}$. The treated molten metal are then transferred into the pouring ladle where the first inoculation treatment occurs in the melt stream. The second inoculation treatment is done on the melt stream during discharge into the moulds. The samples are labeled as shown in Table 2. These procedures are maintained for all the treatment temperatures and moulds were cast within six minutes after treatment to avoid fading of inoculants.

\subsection{Hardness Test}

Brinel hardness test is carried out using a 10/3000 kg indentation ball on tester model Foundrax/B.H.D/1003402.

\subsection{Tensile Test}

A computerized universal mechanical testing machine, instron series 3369 is used to determine tensile properties in accordance with ASTM E8 standard. The dimension of test piece is shown in Figure 1.

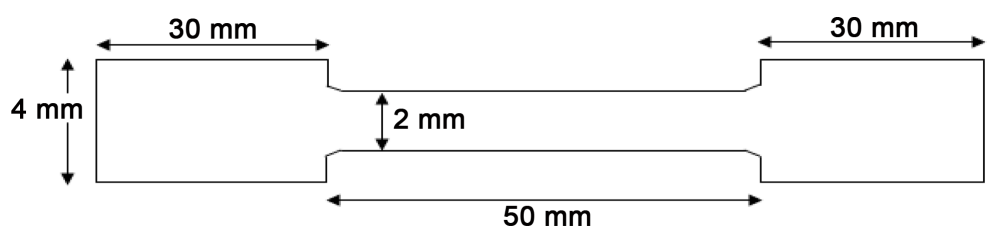

Figure 1. Dimension of tensile test sample.

Table 1. Chemical composition of charge materials.

\begin{tabular}{cccccc}
\hline Charge & Weight \% $(\mathrm{kg})$ & Charge \% & C (Charge Comp.) \% & Si (Charge Comp.) \% & Mn (Charge Comp.) \% \\
\hline Mild Steel & 320 & 64 & 0.1 & 0.1 & 0.2 \\
Ductile Iron Returns & 150 & 30 & 0.1 & 0.1 & 0.2 \\
Ferro-Silicon & 7 & 1.4 & 0.0 & 70 & 0.0 \\
Graphite & 23 & 4.6 & 70 & 0.0 & 0.0 \\
\hline
\end{tabular}

Table 2. Sample designation and treatment temperature.

\begin{tabular}{cccccccc}
\hline S/N Treatment & 1 & 2 & 3 & 4 & 5 & 7 \\
Temperature, ${ }^{\circ} \mathrm{C}$ & 1550 & 1530 & 1510 & 1490 & 1470 & 1450 \\
Sample Name & $\mathrm{T} 1$ & $\mathrm{~T} 2$ & $\mathrm{~T} 3$ & $\mathrm{~T} 4$ & $\mathrm{~T} 5$ & $\mathrm{~T} 6$ \\
\hline
\end{tabular}




\subsection{Morphological Analysis}

Samples for microstructural analysis are cut, ground progressively using 180, 240, 320, 400 and 600 abrasive papers. These are then polished using silk cloth charged with $3 \mu \mathrm{m}$ diamond paste according to standard procedure outlined in ASTM Standard E 3 for metallographic analysis. The prepared samples are viewed in their unetched and etched (using 2\% nital solution) conditions using a CETI Optical Metallurgical Microscope Model No. 0703552 at magnification of $100 \times$.

\section{Results and Discussion}

\subsection{Effect of Treatment Temperature on Hardness Responses of TWDI}

The hardness trend of TWDI with treatment temperatures used is shown in Table 3 and Figure 2. The trend is not uniform, but superior hardness is obtained at lowest temperature of $1450^{\circ} \mathrm{C}$ for 2,3 and $4 \mathrm{~mm}$ thick samples, while $1550^{\circ} \mathrm{C}$ have the lowest values.

\subsection{Effect of Treatment Temperature on Tensile Strength of TWDI}

Figures 3-5 show the patterns of Ultimate tensile stress, percent elongation and percent elongation at UTS respectively with treatment temperature. In Figure 3, the sinusoidal UTS pattern have peak UTS of 389, 409 and $514 \mathrm{MPa}$ for 2, 3 and $4 \mathrm{~mm}$ thicknesses respectively, achieved at $1450^{\circ} \mathrm{C}$ which corresponds to the second lowest treatment temperature after $1430^{\circ} \mathrm{C}$ which is the lowest treatment temperature used. This indicates that low treatment temperature of $1450^{\circ} \mathrm{C}$ (tapped at $1455^{\circ} \mathrm{C}$ ) is important to achieve the best UTS value for the nodularization treatment reaction but treating at temperature lower than this $\left(1430^{\circ} \mathrm{C}\right)$ can negatively affect UTS.

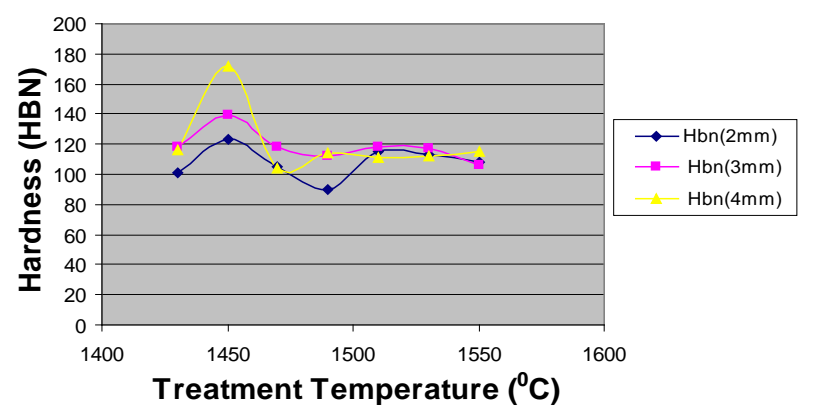

Figure 2. Hardness behaviour of TWDI with treatment temperature.

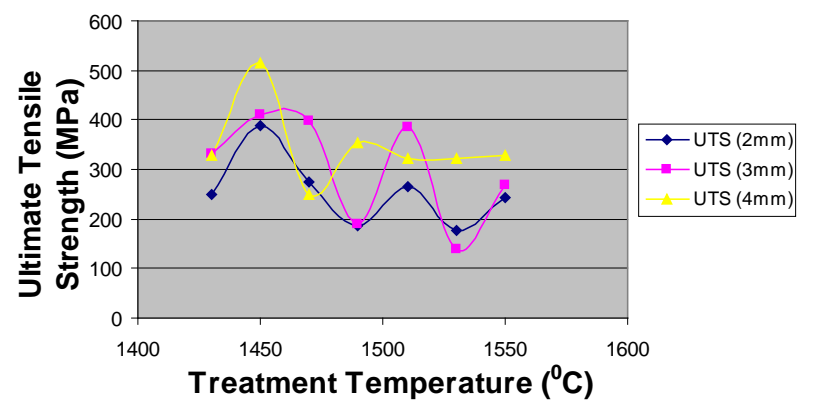

Figure 3. UTS of TWDI castings with treatment temperature.

Table 3. HBN values of cast samples with treatment temperature.

\begin{tabular}{cccccccc}
\hline Treatment Temperature $\left({ }^{\circ} \mathrm{C}\right)$ & 1430 & 1450 & 1470 & 1490 & 1510 & 1530 & 115 \\
HBN (2 mm) & 101 & 123 & 105 & 90 & 113 & 118 \\
HBN (3 mm) & 118 & 139 & 118 & 112 & 108 \\
HBN (4 mm) & 116 & 172 & 104 & 114 & 111 & 112 \\
\hline
\end{tabular}




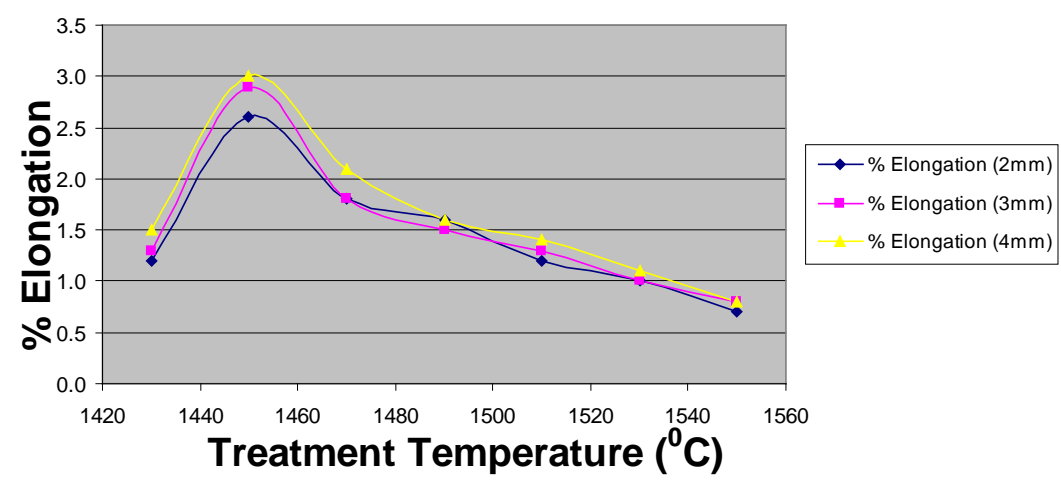

Figure 4. Percent elongation of TWDI castings with treatment temperature.

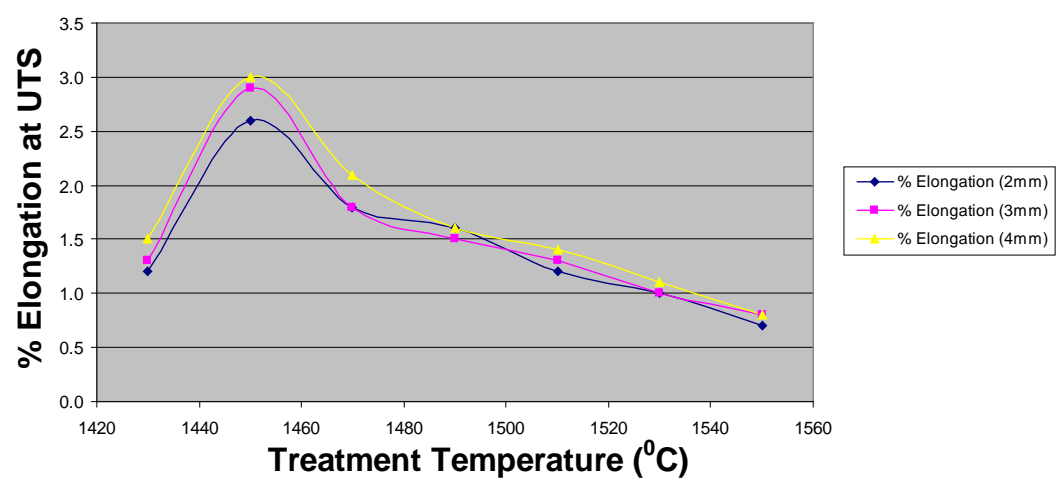

Figure 5. Percent elongation at UTS of TWDI castings with treatment temperature.

The percent elongation as shown in Figure 4 has a defined pattern with treatment temperature significantly imacting on ductility. Treatment temperature of $1550^{\circ} \mathrm{C}$ results in percent elongations of $0.7,0.8$ and 0.8 for 2, 3 and $4 \mathrm{~mm}$ thicknesses respectively. In the treatment temperature of $1450^{\circ} \mathrm{C}$, percent elongation improved significantly to 2.6, 2.9 and 3.0 for 2, 3 and $4 \mathrm{~mm}$ respectively. This indicates that low treatment temperature of $1450^{\circ} \mathrm{C}$ favours better nucleation of graphite structures, better nodule count and nodularity. These three parameters have direct bearing on ductility. The best ductility of 2.6, 2.9 and 3.0 is achieved at $1450^{\circ} \mathrm{C}$ for all the three thicknesses investigated. Treatment at $1430^{\circ} \mathrm{C}$ had negative effect on nodule count and nodularity as is seen from the lower percent elongation values observed for the three thicknesses (1.2, 1.3 and 1.5).

\subsection{Effect of Treatment Temperature on Morphology of TWDI}

The microstructures of samples TI (2, 3, 4 mm) Figures 6-8 show the existence of irregularly-shaped (non-nodular) graphite structures resulting in poor nodularity, low nodule count with carbide precipitates in the etched micrograph. Thus, the yield of the treatment at the treatment temperature of $1550^{\circ} \mathrm{C}$ is greatly impaired. The T2 range of samples, Figures 9-11 also show the same trend. In T2, 2 mm section sample shown in Figure 9, in addition to poor nodule count and nodularity, shows the existence of shrinkage porosity in its structure. This is due to insufficient nuclei for the precipitation of graphite structures. The carbide phase in the T3 range reduces compared to the T1 and T2 samples in Figures 12-14. The T3, 2 mm sample also shows the presence of non-nodular graphite structures and carbide precipitates. In T3, $3 \mathrm{~mm}$ the matrix contains large proportion of irregular shaped graphite structures. Improved nodularity, nodule count and reduction of the carbide phase are observed for T4 T6 range of samples in Figures $15-23$. The best morphologies are achieved for the T5 $\left(1470^{\circ} \mathrm{C}\right)$ and $\mathrm{T} 6\left(1450^{\circ} \mathrm{C}\right)$ samples, where good nodularity of graphite sizes 5, 6 and 7, high nodule count and absence of carbide precipitates are observed in pearlite-ferrite matrix. This structure explains the earlier superior hardness, UTS and percent elongation values obtained and shown in Figures 2-4. A lower treatment temperature of $1430^{\circ} \mathrm{C}$ obviously had negative effect on microstructure of TWDI as seen in Figures 24-26 where carbide precipitates and nonnodular graphite structures is evident. This structure explains the drop in percent elongation in Figure 4. 


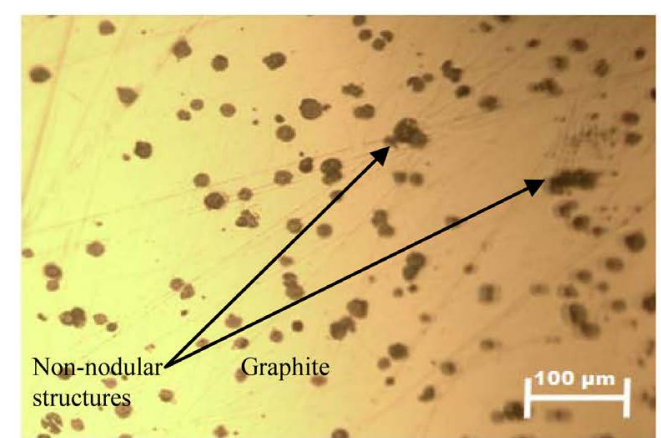

(a)

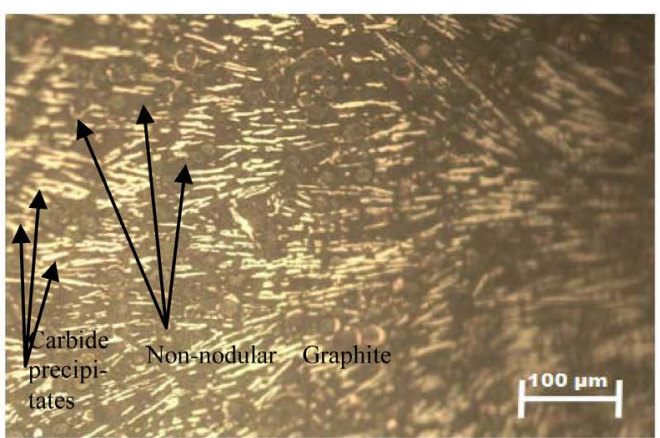

(b)

Figure 6. Micrographs of $2 \mathrm{~mm}$ T1 sample (a) Unetched and (b) Etched.

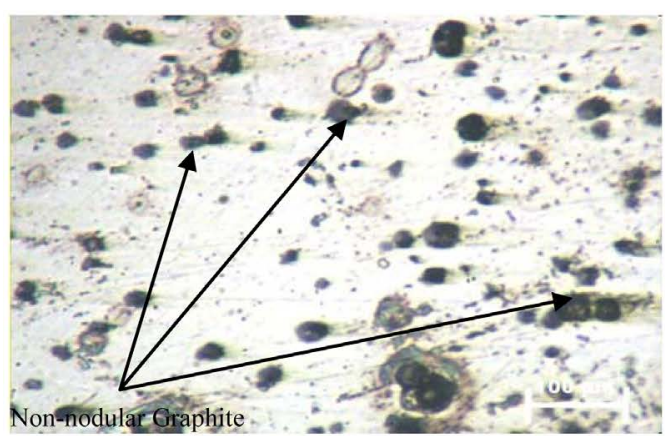

(a)

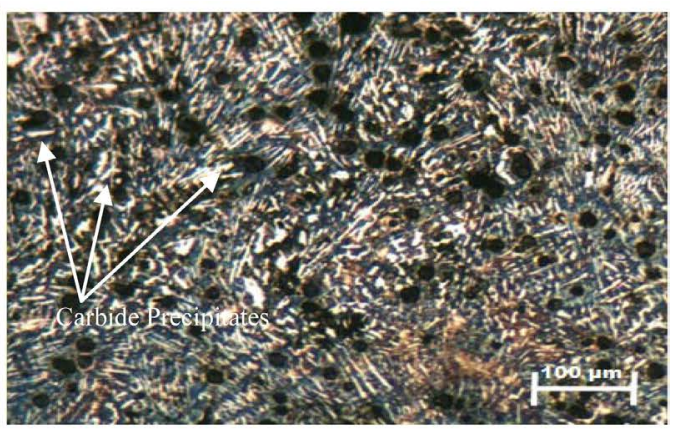

(b)

Figure 7. Micrographs of $3 \mathrm{~mm}$ T1 sample (a) Unetched and (b) Etched.

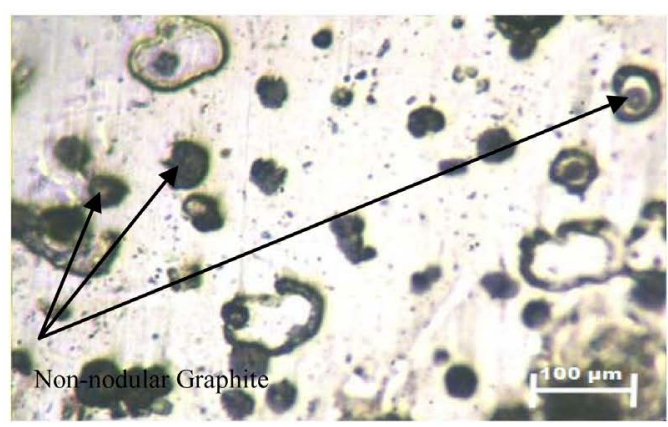

(a)

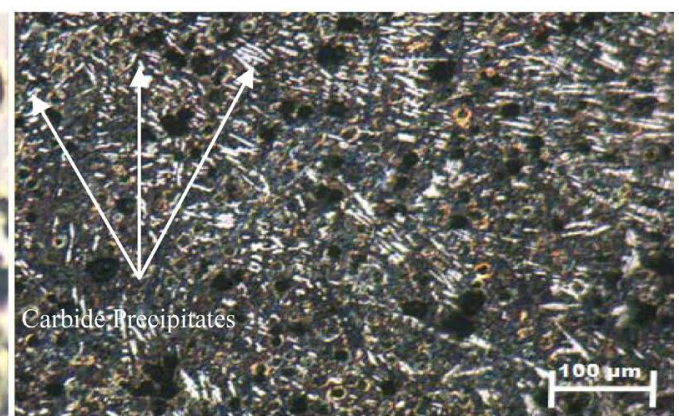

(b)

Figure 8. Micrographs of $4 \mathrm{~mm}$ T1 sample (a) Unetched and (b) Etched.

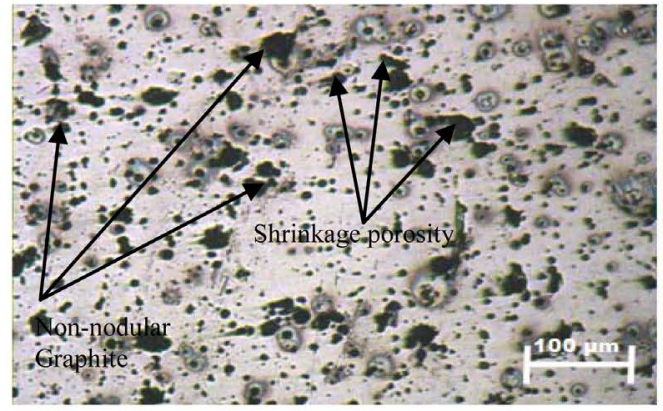

(a)

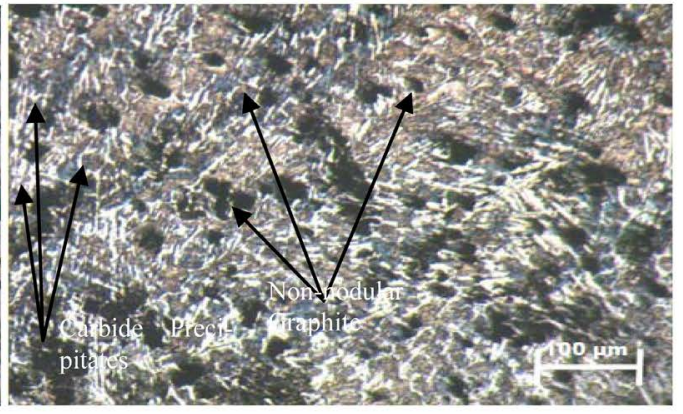

(b)

Figure 9. Micrographs of 2 mm T2 sample (a) Unetched and (b) Etched. 


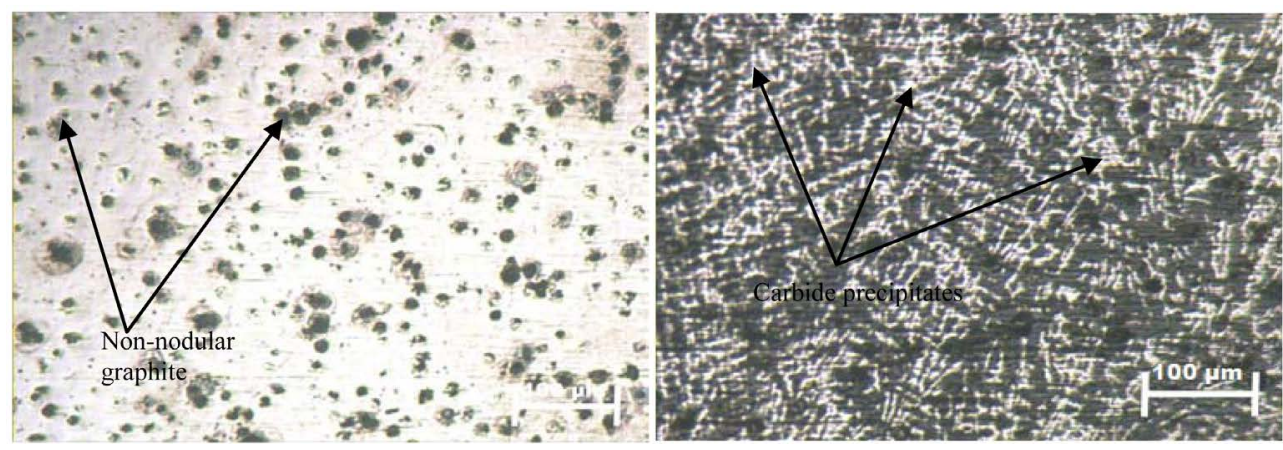

(a)

(b)

Figure 10. Micrographs of 3 mm T2 sample (a) Unetched and (b) Etched.

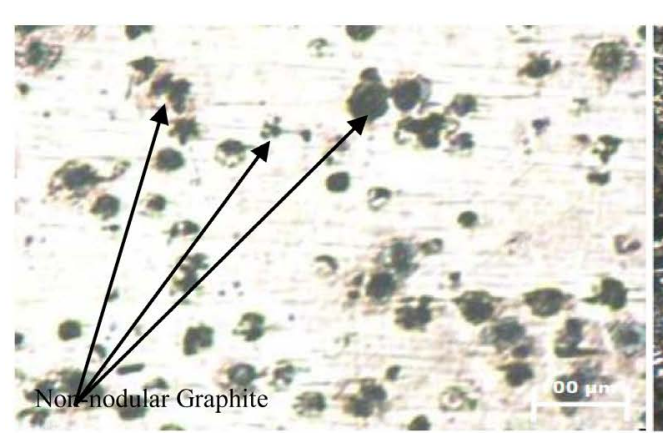

(a)

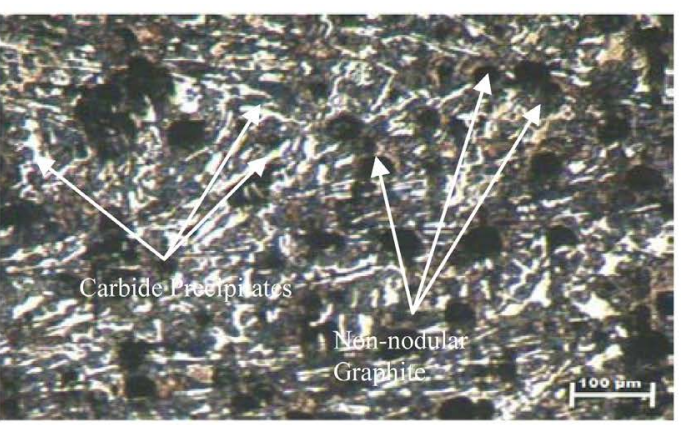

(b)

Figure 11. Micrographs of $4 \mathrm{~mm}$ T2 sample (a) Unetched and (b) Etched.

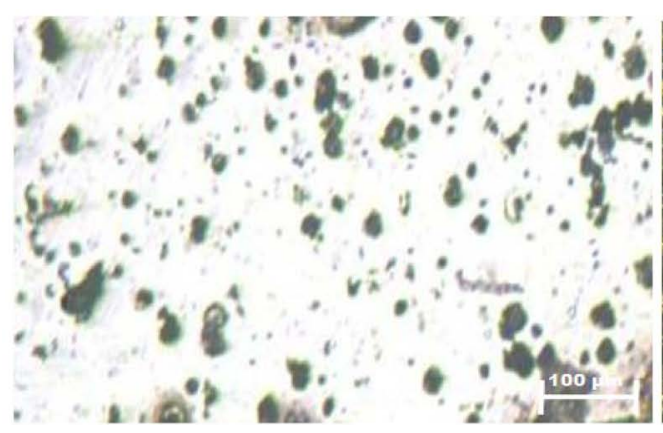

(a)

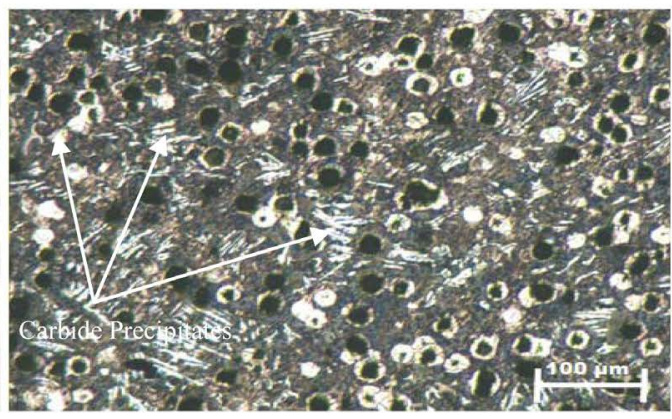

(b)

Figure 12. Micrographs of 2 mm T3 sample (a) Unetched and (b) Etched.

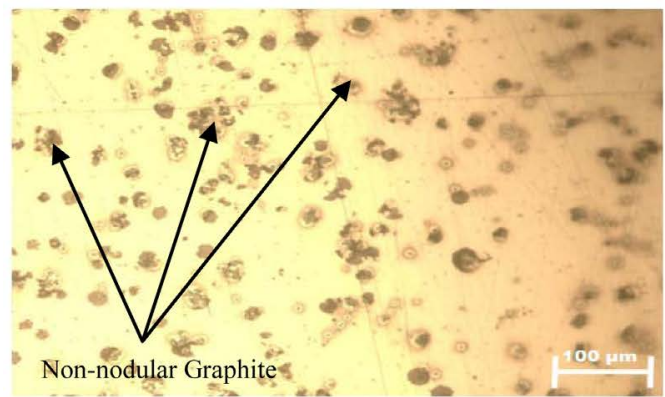

(a)

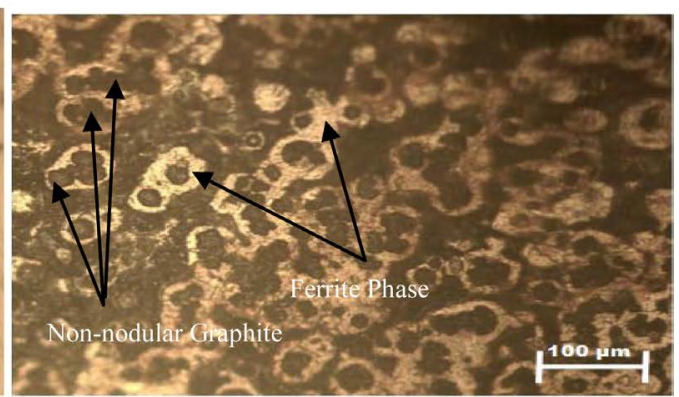

(b)

Figure 13. Micrographs of $3 \mathrm{~mm}$ T3 sample (a) Unetched and (b) Etched. 


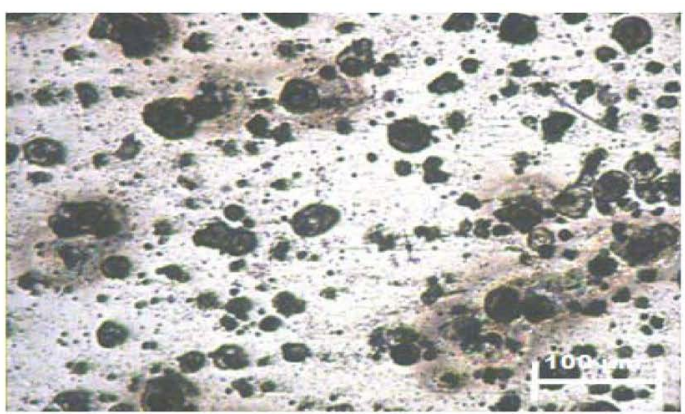

(a)

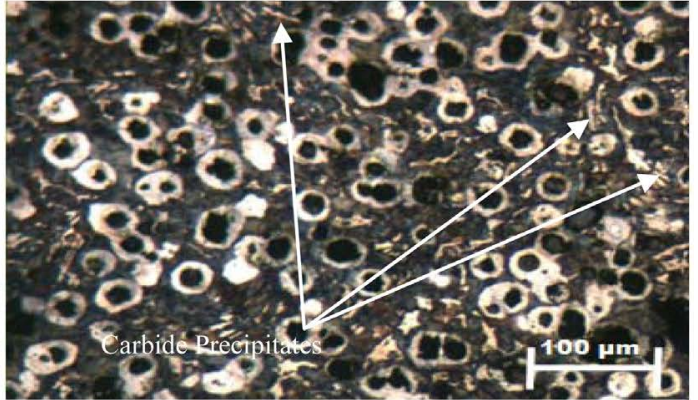

(b)

Figure 14. Micrographs of 4 mm T3 sample (a) Unetched and (b) Etched.

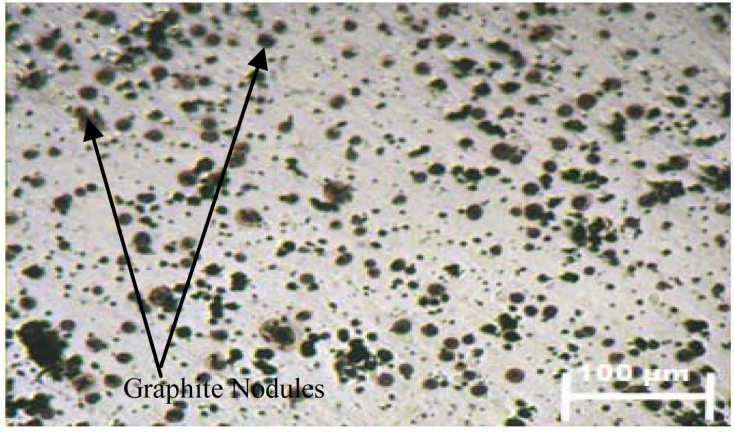

(a)

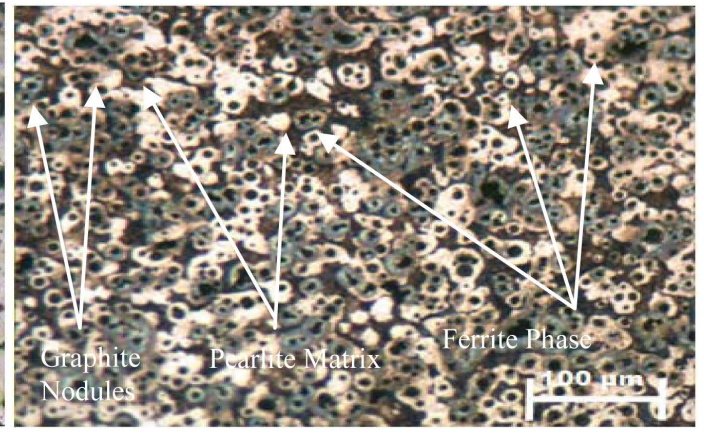

(b)

Figure 15. Micrographs of $2 \mathrm{~mm}$ T4 sample (a) Unetched and (b) Etched.

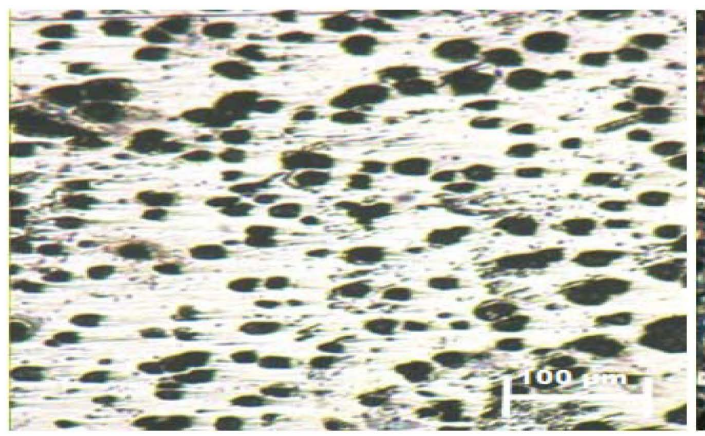

(a)

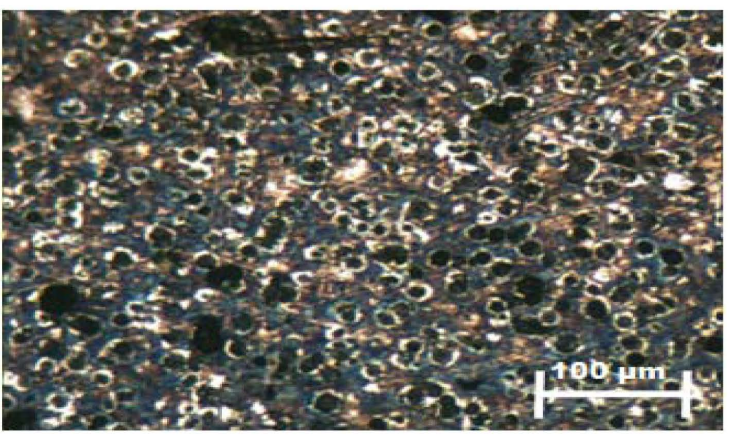

(b)

Figure 16. Micrographs of $3 \mathrm{~mm}$ T4 sample (a) Unetched and (b) Etched.

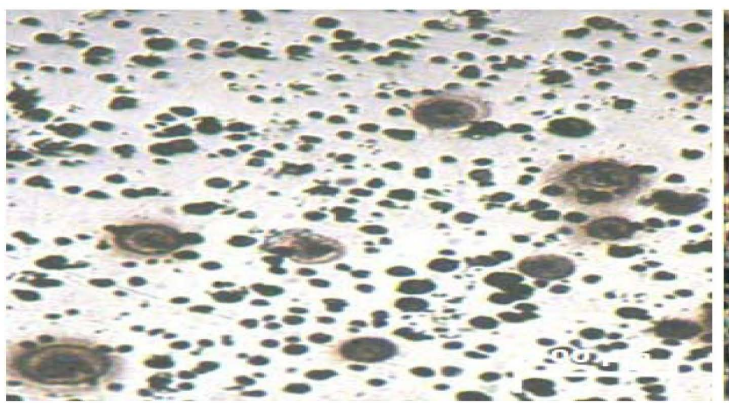

(a)

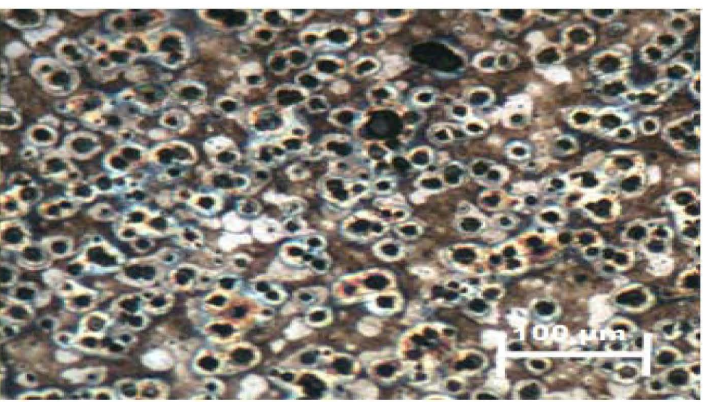

(b)

Figure 17. Micrographs of $4 \mathrm{~mm}$ T4 sample (a) Unetched and (b) Etched. 


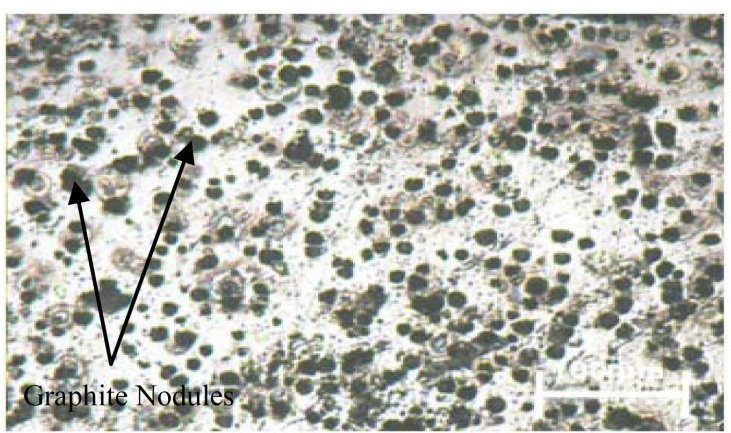

(a)

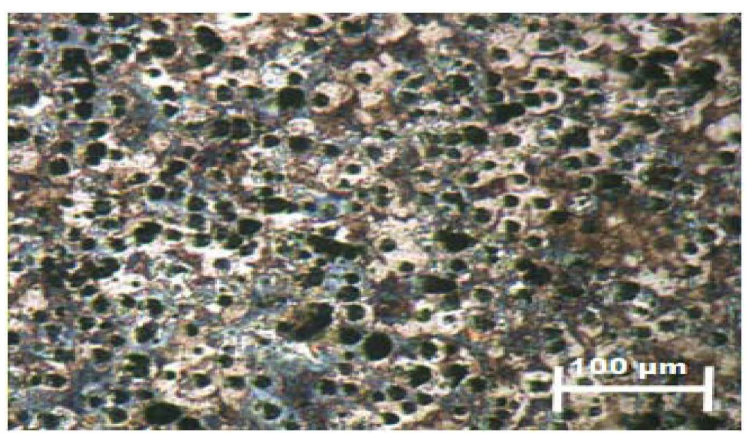

(b)

Figure 18. Micrographs of $2 \mathrm{~mm}$ T5 sample (a) Unetched and (b) Etched.

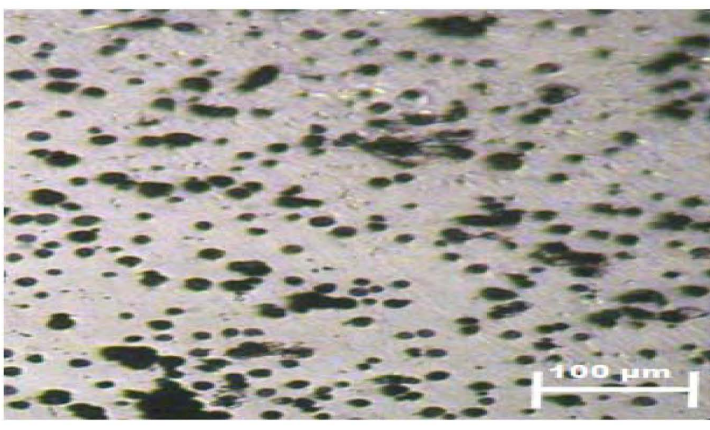

(a)

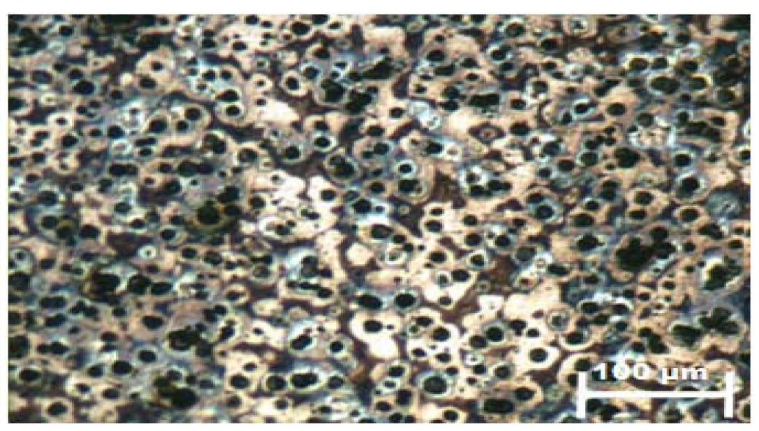

(b)

Figure 19. Micrographs of 3 mm T5 sample (a) Unetched and (b) Etched.

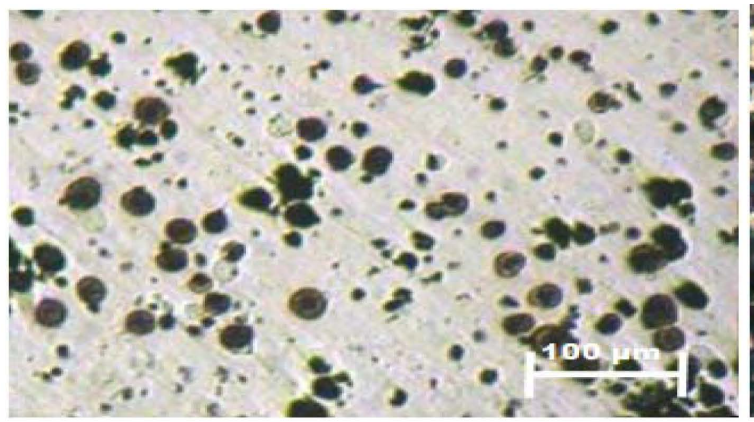

(a)

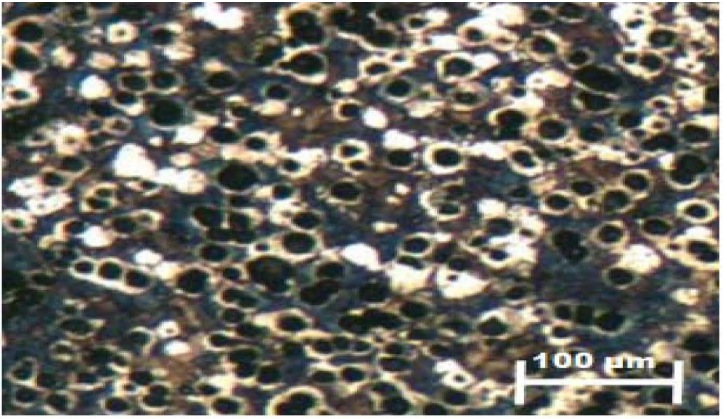

(b)

Figure 20. Micrographs of $4 \mathrm{~mm}$ T5 sample (a) Unetched and (b) Etched.

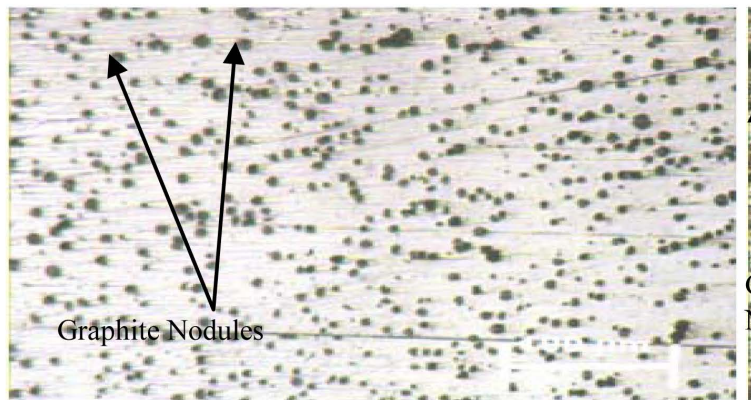

(a)

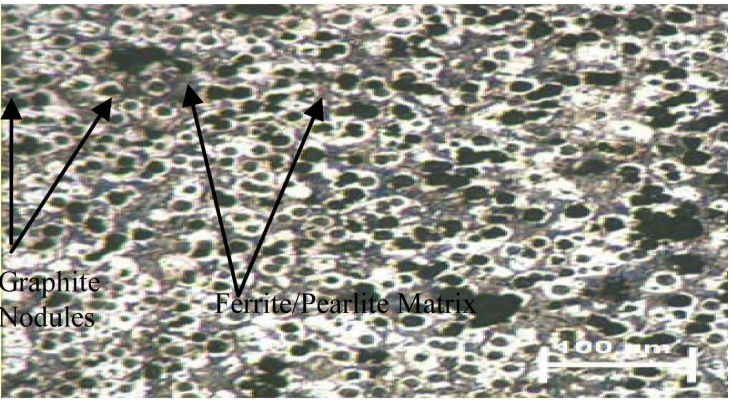

(b)

Figure 21. Micrographs of 2 mm T6 sample (a) Unetched and (b) Etched. 


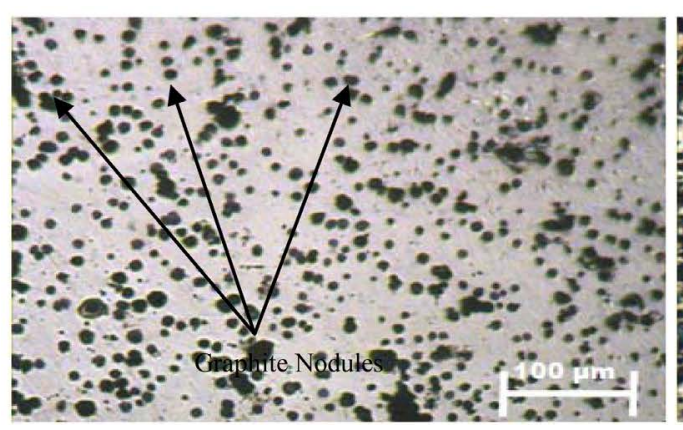

(a)

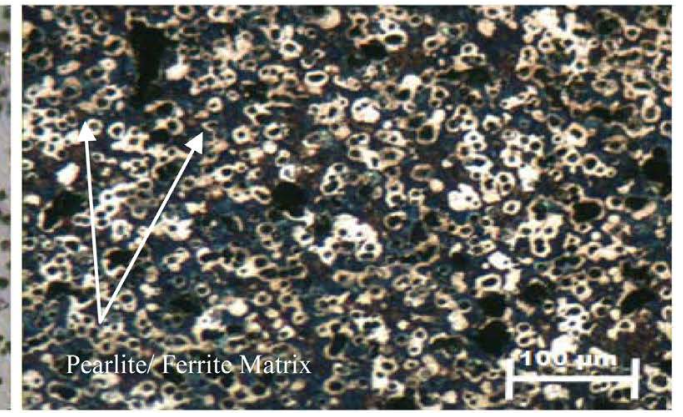

(b)

Figure 22. Micrographs of 3 mm T6 sample (a) Unetched and (b) Etched.

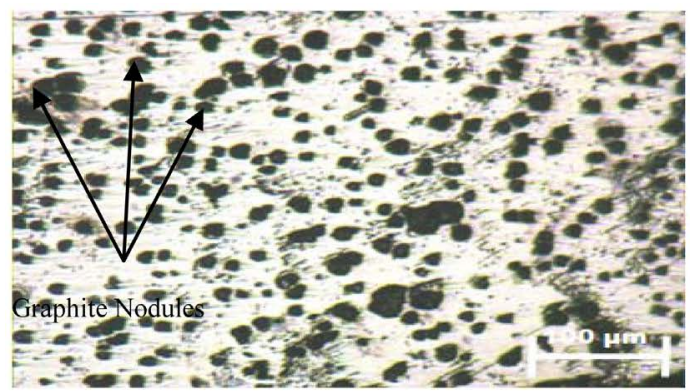

(a)

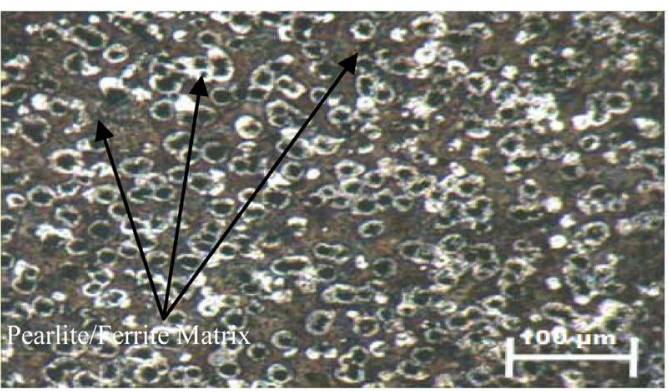

(b)

Figure 23. Micrographs of $4 \mathrm{~mm}$ T6 sample (a) Unetched and (b) Etched.

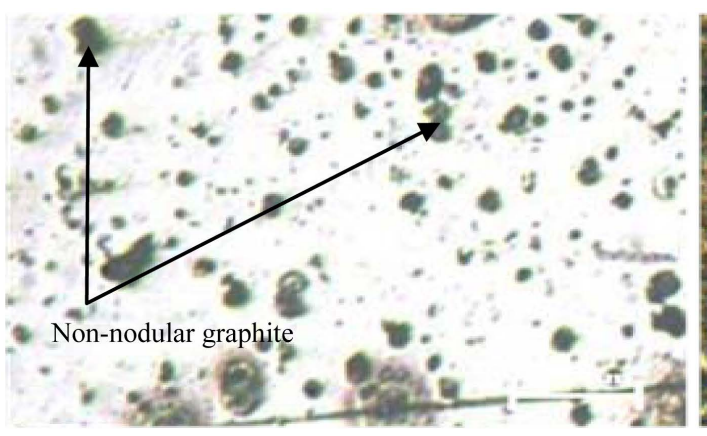

(a)

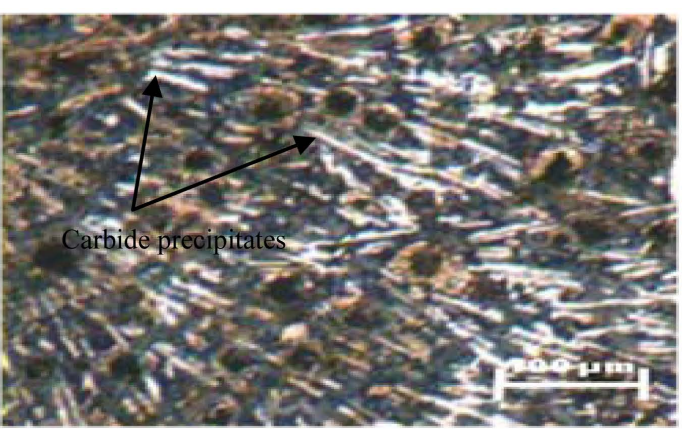

(b)

Figure 24. Micrographs of 2 mm T7 sample (a) Unetched and (b) Etched.

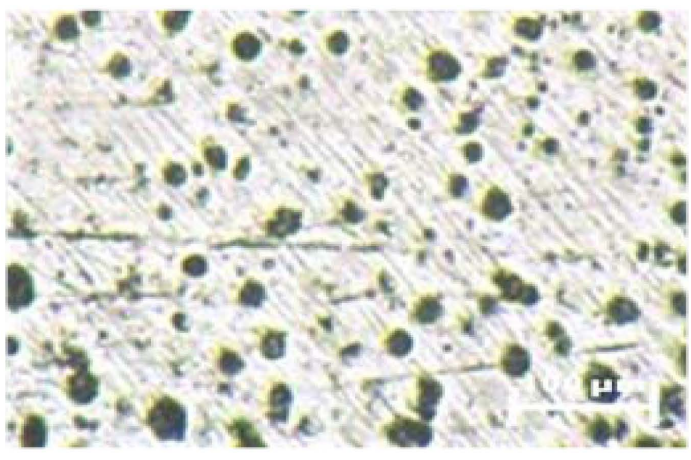

(a)

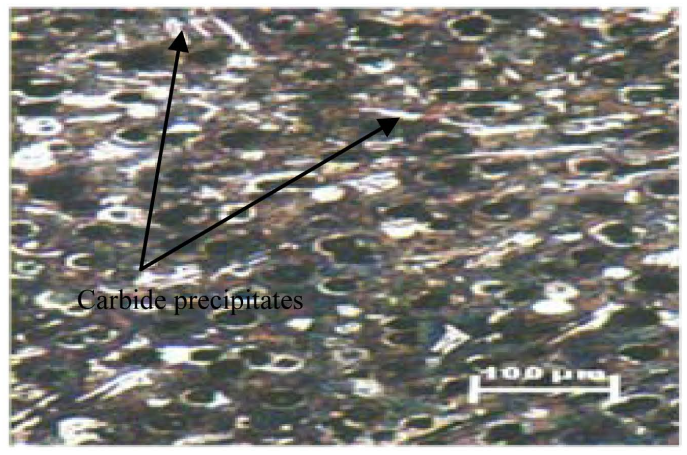

(b)

Figure 25. Micrographs of 3 mm T7 sample (a) Unetched and (b) Etched. 


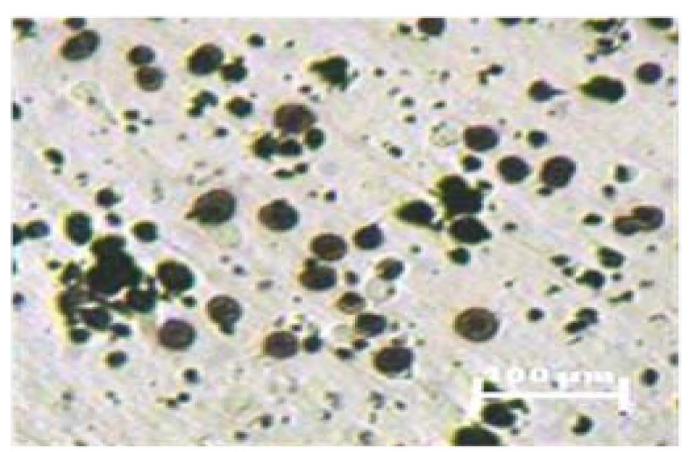

(a)

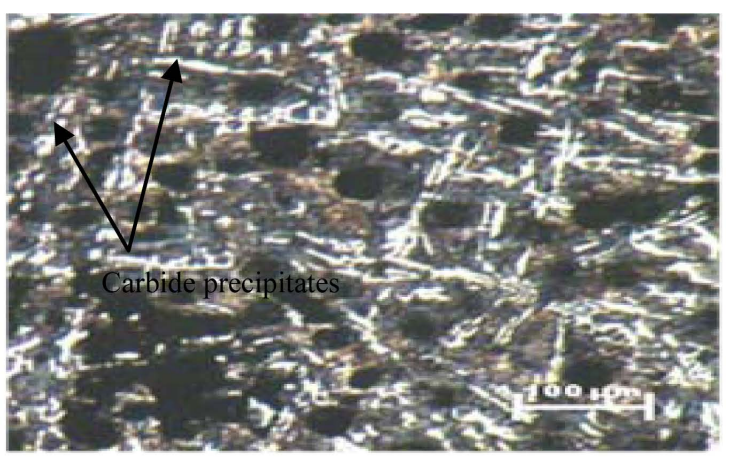

(b)

Figure 26. Micrographs of 4 mm T7 sample (a) Unetched and (b) Etched.

\section{Conclusions}

This study has shown that it is possible to obtain carbide free, good nodularity and nodule count in thin wall ductile iron castings through in ladle sandwich nodularization treatment method accompanied by two step inoculation treatment.

Lower treatment temperatures of $1450^{\circ} \mathrm{C}$ and $1470^{\circ} \mathrm{C}$ promote magnesium recovery, better microstructure and mechanical properties, but treatment temperature as low as $1430^{\circ} \mathrm{C}$ is unfavourable as mechanical properties became significantly impaired. The higher temperatures of $1530^{\circ} \mathrm{C}$ and $1550^{\circ} \mathrm{C}$ produce unfavourable microstructure and poor mechanical properties.

Treatment temperature of $1450^{\circ} \mathrm{C}$ results in carbide free matrix, good nodularity and nodule count structure with 123, 139 and $172 \mathrm{HBN}, 389,409$ and $514 \mathrm{MPa}$ tensile strengths, 2.6\%, 2.9\% and 3.0\% elongation for 2, 3 and $4 \mathrm{~mm}$ thick samples respectively.

\section{Acknowledgements}

The authors gratefully thank the Management and Staff of Nigerian Foundries Ltd, Lagos, Nigeria, for their assistance in the use of their facilities. The contributions of Staff of Metallurgical Laboratory of the Department of Metallurgical and Materials Engineering, University of Lagos are recognized.

\section{References}

[1] Skaland, T. (2003) A New Method for Chill and Shrinkage Control in Ladle Treated Ductile Iron. Keith Millis Symposium on Ductile Cast Iron.

[2] Fras, E. and Gorny, M. (2006) Structure of Thin Wall Austempered Ductile Iron (TWADI). Proceedings of the 8th International Symposium on Science and Processing of Cast Iron, Beijing, 16-19 October 2006, 157.

[3] Borrajo, J.M., Martinez, R.A., Boeri, R.E. and Sikora, J.A. (2002) Shape and Count of Free Graphite Particles in Thin Wall Ductile Iron Castings. ISIJ International, 42, 257-263. http://dx.doi.org/10.2355/isijinternational.42.257

[4] Ashraf Sheikh, P.M. (2008) Production of Carbide-Free Thin Ductile Iron Castings. Journal of University of Science and Technology Beijing.

[5] Skaland, T., Grong, O. and Grong, I. (1993) A Model for Graphite Formation in Ductile Iron Inoculation Mechanisms. Metallurgical and Materials Transaction, 24A, 2321-2345.

[6] Flemings, M.C. (1974) Solidification Processing. McGraw-Hill Book Company, New York, 423.

[7] Bockus, S., Venckunas, A. and Zaldarys, G. (2008) Relation between Section Thickness, Microstructure and Mechanical Properties of Ductile Iron Castings. Materials Science, 14.

[8] Stefanescu, D.M., Ruxanda, R. and Dix, L.P. (2003) The Metallurgy and Tensile Mechanical Properties of Thin Wall Spheroidal Graphite Iron. International Journal of cast Metals Research, 16, 319-324.

[9] Bockus, S. and Zalgarys, G. (2009) Influence of the Section Size and Holding time on the Graphite Parameters of Ductile Iron Production. Metallurgija, 48, 19-22.

[10] Bockus, S. and Dobrovolskis, A. (2004) Peculiarity of Producing Ferritic Ductile Iron Castings. Materials Science, 10.

[11] Olsen, S.O. (2009) Inoculation of Grey and Ductile Iron, a Comparison of Nucleation Sites and Some Practical Advis- 
es. AFS Transaction. Technical Report (Online). http://www.foundry.elkem.com/dav/cfblea46e2.pdf

[12] Mullins, J.D. (2006) The Most Important Part of Ductile Iron Production-Inoculation. Sorelmetal Technical Services.

[13] Imasogie, B.I., Afonja, A.A. and Ali, J.A. (2000) Properties of Ductile Iron Nodularised with Multiple Calcium Magnesium Based Master Alloy. Materials Science and Technology, 16, 194-201. http://dx.doi.org/10.1179/026708300101507541

[14] Hsu, C-H., Chen, M-L. and Hu, C-J. (2007) Microstructure and Mechanical Properties of 4\% Cobalt and Nickel Alloyed Ductile Iron. Materials Science and Engineering: A, 444, 339-346. http://dx.doi.org/10.1016/j.msea.2006.09.027

[15] Choi, J.H., Oh, J.K., Choi, C.O., Kim, J.K. and Rohatgi, P.K. (2004) Effect of Rare Earth Elements on Microstructure Formation and Mechanical Properties of Thin Wall Ductile Iron Castings. Journal of Material Science and Engineering: A, 383, 323-333. http://dx.doi.org/10.1016/j.msea.2004.04.060

[16] Ashraf Skeikh, M. and Iqbal, J. (2007) Effect of Lanthanum on Nodule Count and Nodularity of Ductile Iron. Journal of Rare Earths, 25, 533-536. http://dx.doi.org/10.1016/S1002-0721(07)60557-2

[17] Olsen, S.O. and Hartung, C. (2006) Recovery of Magnesium in a Ductile Iron Process. Elkem Foundry Products, New Presentation Folder, Kristiansand.

[18] Gagne, M. (2006) Thin Wall Ductile Iron Castings: A Reality for Light Weight Automotive Parts. Sorelmetal Technical Services. 